\title{
Ginger 'S Role in A Hepatic Lead Toxicity Model
}

\author{
Original \\ Article \\ Asmaa Mohamed Yousef, Mohey Elsaid Hulail and Enssaf Ahmad Ahmad
}

Human Anatomy and Embryology Department, Zagazig University, Sharkia, Egypt.

\begin{abstract}
Background: Lead toxicity is a multi-organ risk. It represents a worldwide threat for a very long time ago due to its unavoidable exposure near industrial areas although of all precautions applied. Ginger proved to have an antioxidant effect through its chemical components and so it is adopted in many therapeutic forms.

Aim of the study: This study was to explore the proposed protective effect of ginger on hepatic vascular changes and toxicity resulting from environmental exposure to lead.

Material and methods: Thirty-two adult male albino rats (weighs 150-200gm) were used in the present study for 8 weeks. The animals were divided into four groups. Group I is a -ve control group received distilled water only by gavage, group II is a +ve control group received $500 \mathrm{mg} / \mathrm{kg} \mathrm{BW}$ ginger in distilled water by gavage, group III was treated with $60 \mathrm{mg} / \mathrm{kg} \mathrm{BW}$ lead acetate (LA) by gavage and group IV was treated by both doses of LA and ginger with gavage. After 8 weeks, animals of all groups were sacrificed and their livers were dissected, weighed and finally processed for light microscopic; HandE and immunohistochemical studies using the anti-apoptotic Bcl2 Immuno-staining.

Results: In the HandE and immune stained liver slides, the destructive effect of lead toxicity on liver of group III was obvious. Marked loss of the normal liver architecture with variable hepatocellular changes, necrotic foci and marked vascular affection were detected. These were mostly un-recognized in those rats co-treated with ginger (group IV) that showed almost a normal liver architecture with slightly dilated central veins. This proved to be of statistical significance when compared among the four groups.
\end{abstract}

Conclusion: Ginger proved statistically to be protective to both vascular and parenchymatous architecture in cases of hepatic lead toxicity.

Received: 13 February 2018, Accepted: 09 July 2018

Key Words: Antioxidant; Bcl-2 Immunohistochemical; hepatocytes; hepatic vasculature; protective; portal area.

Corresponding Author: Enssaf Ahmad Ahmad, MD, Human Anatomy and Embryology Department, Zagazig University, Sharkia, Egypt, Tel.: +20 1119943083,E-mail: EAAbdelhamid@medicine.zu.edu.eg; d_enaa@yahoo.com

ISSN: 1110-0559, Vol. 41, No. 4

\section{INTRODUCTION}

Exposure to lead via inhalation and consumption of contaminated water is one of the oldest toxins in the environment $t^{[1,2]}$.

Lead is toxic for almost all body organs even in minimal doses ${ }^{[2,3]}$ through its oxidative stress effect. This oxidative stress is attributed to increasing malondialdehyde (MDA) content and reactive oxygen species (ROS) from mitochondria which might end in apoptotic damage of the tissues ${ }^{[4,5]}$. Liver is one of the most affected organs that undergoes cellular necrosis and impaired functions and considered a major target of lead toxicity ${ }^{[6-8]}$. Lead toxicity leads to macro-vascular steatosis, hepatocyte injury, bile canaliculi dilatation and bile stasis. It also affects cholesterols regulation, free fatty acids and phospholipids. It also increases pro-apoptotic proteins, mainly Bax and leads to abnormal expression of genes ${ }^{[9]}$.

Ginger (Family Zingiberaceae) is widely used flavor and cookery agent world wide. Its components of gingerdiol, gingerol, quercetin and zingiberene makes it a powerful antioxidant because of their scavenging effect on hydroperoxide, superoxide anion and hydroxyl free radicals. Also they inhibit both (NO) synthesis and lipid peroxidation (LPO $)^{[10,11]}$. It is used as a herbal treatment in many medical cases as; sprains, arthritis, muscular aches, rheumatism, vomiting, indigestion, infectious diseases, hypertension and many other conditions. Therefore, it is a safe herbal supplement that has minimal side effects ${ }^{[12-14]}$.

\section{MATERIAL AND METHODS}

\section{Experimental animals:}

Thirty-two adult male albino rats, each weighs about 150-200gm, were used in the present study. They were bred in animal house and laboratories of Faculty of Medicine, Zagazig University. They were housed at a temperature-controlled and light-controlled room (12-h light/dark cycle), with free access to food and water. All experimental procedures were performed in accordance with the guidelines of the Institutional Animal Care and Use Committee of Faculty of Medicine, Zagazig University.

\section{Experimental design:}

The animals were randomly divided into four equal groups, 
passing an 8 weeks experiment. The 8 rats of group I (-ve control group) received distilled water by gavage only. The 8 rats of group II (Ginger treated group or the +ve control group) received a daily dose of ginger $(500 \mathrm{mg} / \mathrm{kg} \mathrm{BW})$ dissolved in distilled water by gavage ${ }^{[15]}$. The 8 rats Group III (Lead acetate treated group) received a daily dose of lead acetate $(60 \mathrm{mg} / \mathrm{kg}$ BW) dissolved in distilled water by gavage ${ }^{[16]}$. Lead acetate was obtained in the powder form. Laparotomy was performed and the liver was dissected out carefully from each animal, weighed and finally processed at National Oncology Institute, Cairo for light microscopic and immunohistochemical studies.

\section{Microscopic imaging:}

Light Microscopic study was carried out in two categories, 1 st one is haematoxylin and eosin stained ${ }^{[17]}$ and the other stained by Bcl-2 Immunostaining to detect the anti- apoptotic factor Bcl-2 protein ${ }^{[18]}$.

\section{Morphometry:}

The collected pictures were processed by Image analysis and morphometric study by measuring the area percentage of immune reaction of Bcl-2 using NIH Image J (v1.50) image analysis software. Non-overlapping fields from each slide were selected randomly and analyzed. The diameters of central vein were measured using Digimizer 4.3.2. Image analysis software (MedCalc Software bvba, Belgium) available in Faculty of medicine, Zagazig University.

\section{Statistical analysis:}

Statistical study of the diameter of central vein and immune reaction to Bcl-2 were done. All the values of experiments were represented as mean \pm Standard Deviation (SD). Oneway analysis of variance (ANOVA) was used, followed by Post hoc least significant difference (LSD) test to evaluate the differences between the groups. For all comparison $P<0.05$ was considered as significant difference. All analyses were performed using the IBM SPSS 18.0 software available in Faculty of medicine, Zagazig University.

\section{RESULTS}

\section{Light microscopic examination:}

Examination of hematoxylin and eosin stained sections of liver of group I (-ve control group) as well as those of group II (+ve control group, Ginger treated group) revealed the normal structure of hepatic lobules as tightly packed cords of intact hepatocytes radiating from the central vein. Some hepatocytes are binucleated. Blood sinusoids are lined by intact endothelial cells and scattered irregular kupffer cells with ovoid nuclei in between (Fig. 1).

Normal portal triad is detected. This triad consists of portal vein with large lumen and thin wall, hepatic artery with small lumen and thick wall containing smooth muscle fibers and bile duct (Fig. 2).

Examination of the hematoxylin and eosin stained sections of liver of group III (Lead acetate treated group) shows a marked loss of the normal liver architecture with variable hepatocellular changes. Some hepatocytes are non-nucleated. Variable number of necrotic foci with shrunken, granular, homogeneous and intensely colored hyper-eosinophilic cytoplasm and fragmenting nuclei are seen within the liver parenchyma (Fig. 3, 4).

The portal triad shows dilated congested portal venule, cellular infiltration and proliferation of the wall of bile ductule. Some areas show an obvious increase in the thickness of the hepatic artery wall. Even more, many areas showed duplication or triplets of the structures of the portal triad (Fig. 3). Central vein is dilated, congested and surrounded by mononuclear cellular infiltration. Liver sinusoids are markedly dilated and congested (Fig. 4).

On the other hand, liver treated primarily with ginger shows lower degree of affection in its architecture; lobules are normal. Normal hepatocytes show vesicular nuclei and acidophilic cytoplasm radiating from central vein. Binucleated cells are abundant and portal areas are more or less normal showing normal bile ductules and nearly normal size of portal veins. Cellular infiltration is nearly negligible. No necrotic foci were observed. Concerning the area of central vein, some dilatation is still detected (Fig. 5, 6).

Bcl-2 Immunohistochemical stained sections showed +ve cytoplasmic reaction in both control groups indicating the normal levels of the anti-apoptotic factors. While a moderate immune reaction was detected in group IV (Fig. 7-9) in comparison to the negative immune reaction of group III.

\section{Morphometry and Statistical Analysis}

Statistical study revealed a high significant $(P<0.001)$ increase in mean value of liver weight in-group III when compared with other groups of study. However, there is a non-significant difference $(P>0.05)$ in mean values of liver weight between groups I, II and IV (Tables 1\&2)

The mean diameters of central vein among the four studied groups proved to be of high Statistical significance (Fig. 10)

The LSD showed a highly significant $(P<0.001)$ increase in mean value of the diameter of central vein in group III and group IV when compared to group I and II. There is a highly significant $(P<0.001)$ increase in mean value of the diameter of central vein of group III when compared to group IV (Table 3 ).

The area percentage of Bcl-2 immune reaction among the four studied groups proved to be of high Statistical significant difference (Fig. 11)

LSD showed no significant difference $(\mathrm{P}>0.05)$ in mean values of area percentages (area \%) of hepatocytes with positive Bcl-2 reactions of group II when compared to group I. There is a highly significant $(P<0.001)$ decrease in mean value of area percentages (area \%) of hepatocytes with positive Bcl-2 reactions of group III when compared to group I and II. There is a highly significant $(P<0.001)$ increase in mean value of area percentages (area \%) of hepatocytes with positive $\mathrm{Bcl}-2$ reactions of group IV when compared to group III (Table 4). 


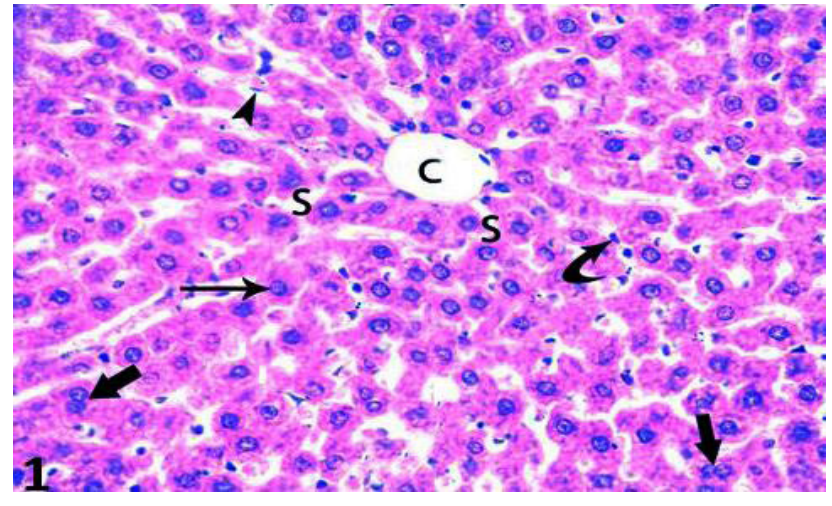

Fig. 1: Photomicrograph of section of liver of control adult male albino rat showing tightly packed cords of polygonal hepatocytes with rounded vesicular nuclei and acidophilic cytoplasm (straight arrow), bi-nucleated hepatocytes (thick arrows), central vein (C). The blood sinusoids (S) show intact endothelial cells with flattened nuclei (arrowhead). Scattered irregular Kupffer cells with ovoid nuclei (curved arrow). (HandE X 400)

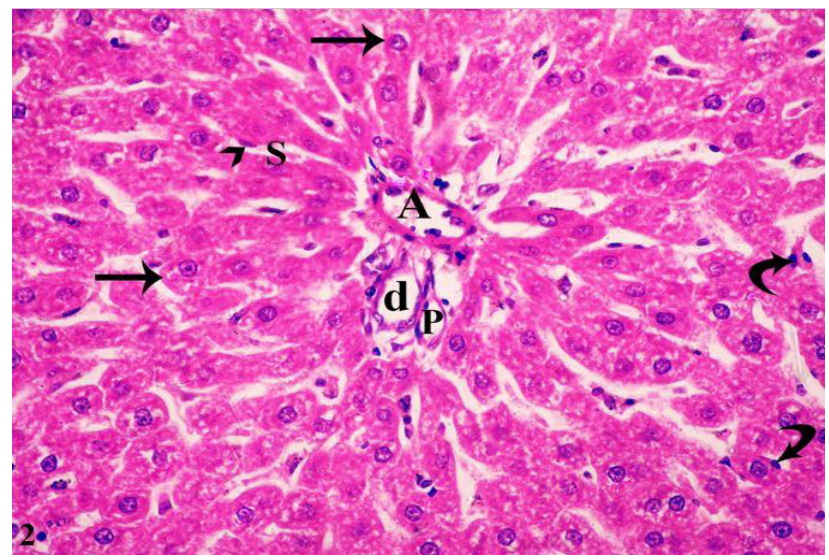

Fig. 2: Photomicrograph of section of liver of control adult male albino rat showing tightly packed cords of polygonal hepatocytes with rounded vesicular nuclei and acidophilic cytoplasm (straight arrow). The blood sinusoids (S) show intact endothelial cells with flattened nuclei (arrowhead), scattered irregular Kupffer cells with ovoid nuclei (curved arrow). Thin walled portal vein (P). Normal bile duct lined by single layer of cuboidal cells with dark rounded nuclei (d). Hepatic artery (A). (HandE X 400)

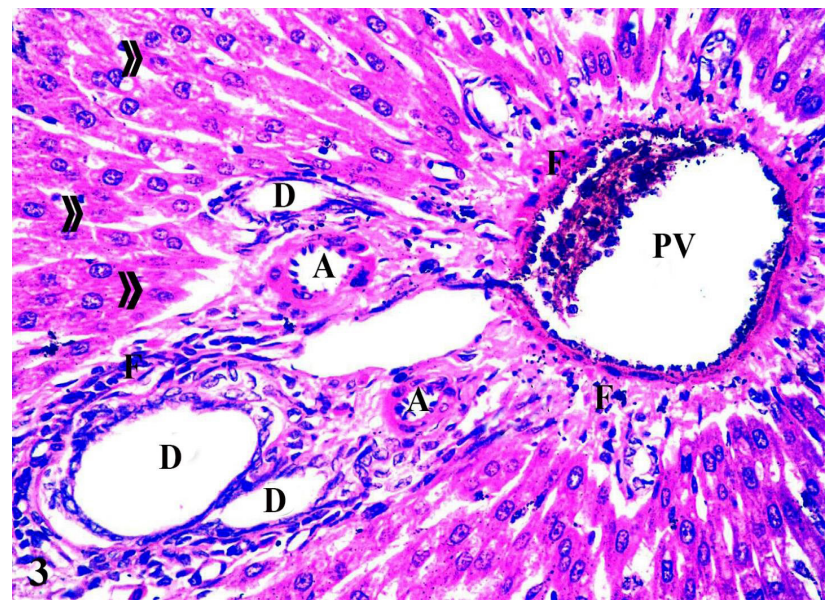

Fig. 3: Photomicrograph of section of liver of group III adult male albino rat showing the region of portal triad. A dilated congested portal vein surrounded by mononuclear cellular infiltration (PV), proliferated bile ducts with large lumen and thickening of their walls (D), proliferated hepatic arteries (A), shrunken cells with hyper-esinophilic cytoplasm and fragmented nuclei (double arrowheads) and cellular infiltration (F) (HandE X 400)

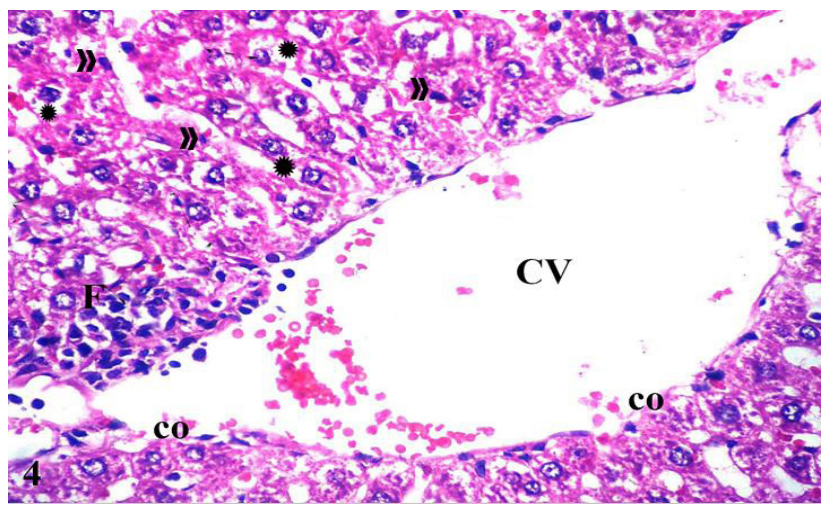

Fig. 4: Photomicrograph of section of liver of group III adult male albino rat showing dilated central vein $(\mathrm{CV})$ with congested lumen and disturbed continuity of its endothelial lining (co) surrounded by cellular infiltration (F). Large hepatocytes with lightly stained foamy vacuolated cytoplasm (asterisk). Some shrunken cells with hyper-esinophilic cytoplasm and nuclear pyknosis are detected (double arrowheads). $\quad$ (HandE X 400)

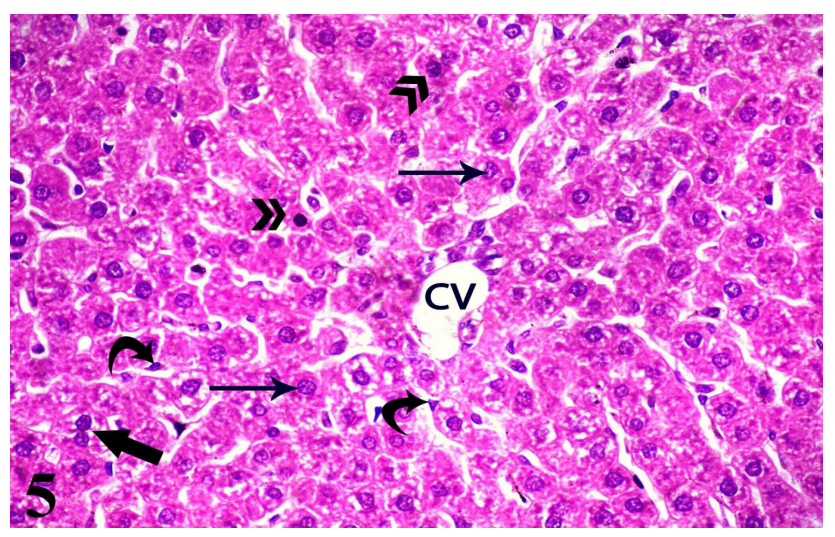

Fig. 5: Photomicrograph of section of liver of group IV adult male albino rat showing tightly packed cords of polygonal hepatocytes with rounded vesicular nuclei and acidophilic cytoplasm (straight arrow), bi-nucleated hepatocytes (thick arrows). Dilated central vein (CV). There is scattered irregular Kupffer cells with ovoid nuclei (curved arrow). Scattered shrunken cells with hyper-esinophilic cytoplasm and nuclear pyknosis are detected (double arrowheads).

(HandE X 400)

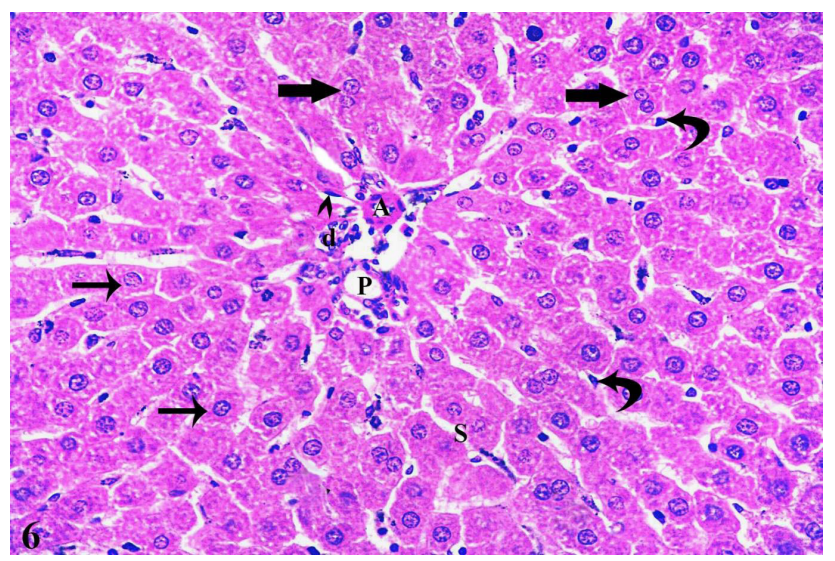

Fig. 6: Photomicrograph of section of liver of group IV adult male albino rat showing tightly packed cords of polygonal hepatocytes with rounded vesicular nuclei and acidophilic cytoplasm (straight arrow), binucleated hepatocytes (thick arrows). The blood sinusoids (S) show intact endothelial cells with flattened nuclei (arrowhead) scattered irregular Kupffer cells with ovoid nuclei (curved arrow). Thin walled portal vein (P), normal bile duct lined by single layer of cuboidal cells with dark rounded nuclei (d) and an intact hepatic artery (A). (HandE X 400) 


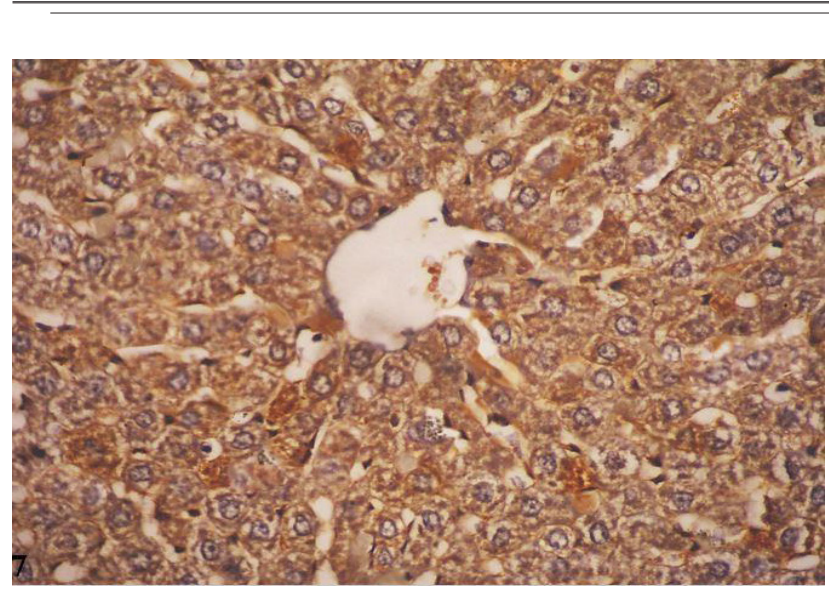

Fig. 7: Photomicrograph of section of the liver of adult male albino rat of control group I showing positive immune reaction for Bcl-2 in the cytoplasm of hepatocytes. The same results were detected in control group II. (Immunohistochemical stain for Bcl-2 X 400)

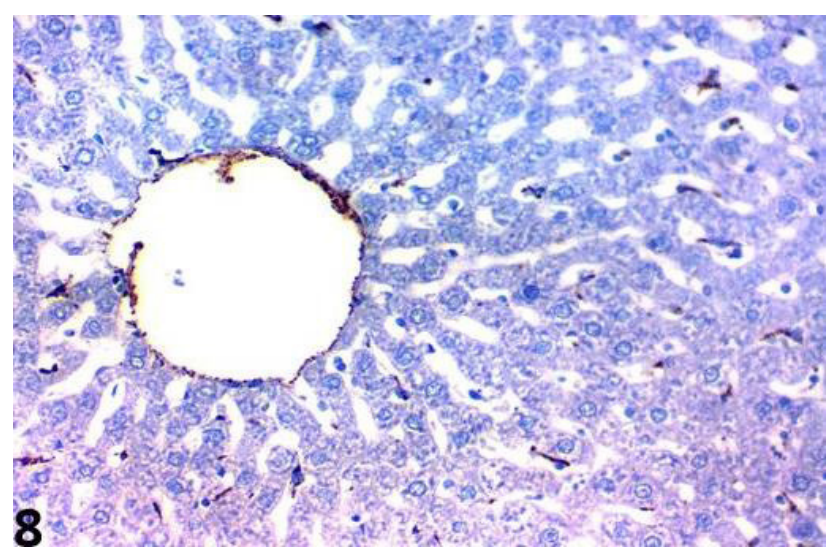

Fig. 8: Photomicrograph of section of the liver of adult male albino rat of group III showing negative immune reaction for Bcl-2 in the cytoplasm of hepatocytes. (Immunohistochemical stain for Bcl-2 X 400)

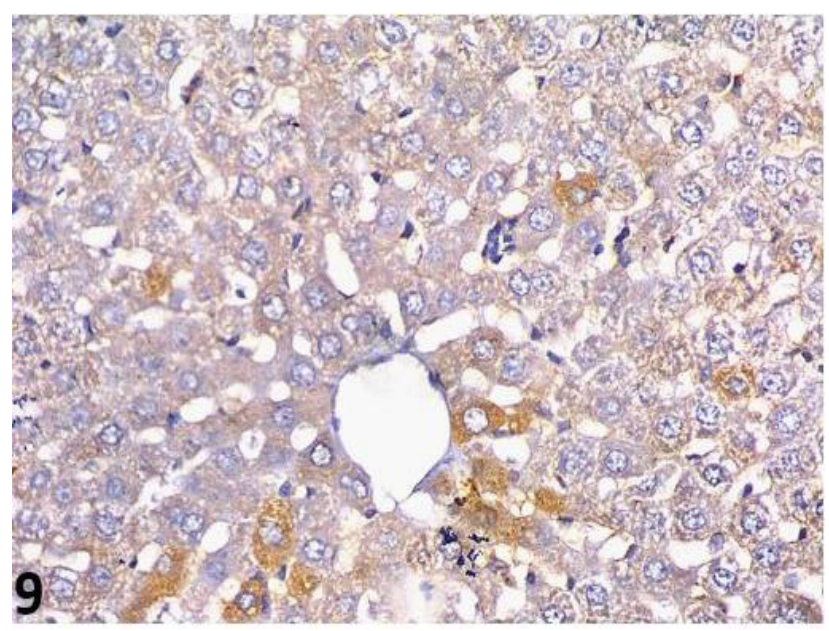

Fig. 9: Photomicrograph of section of the liver of adult male albino rat of group IV showing moderate immune reaction for $\mathrm{Bcl}-2$ in the cytoplasm of hepatocytes. (Immunohistochemical stain for

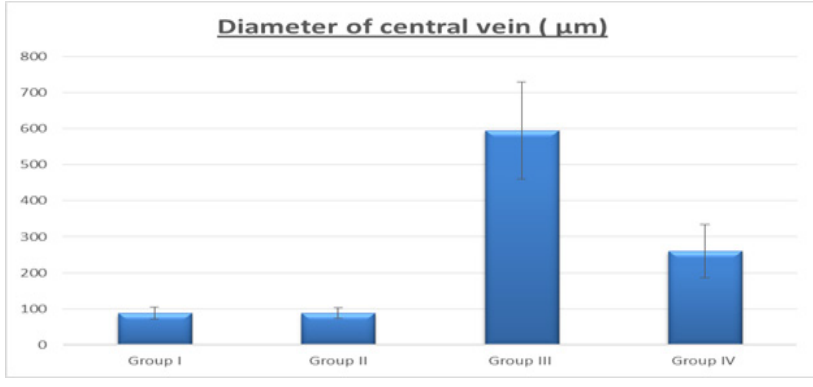

Fig. 10: The diameters of central vein $(\mu \mathrm{m})$ in the four studied groups

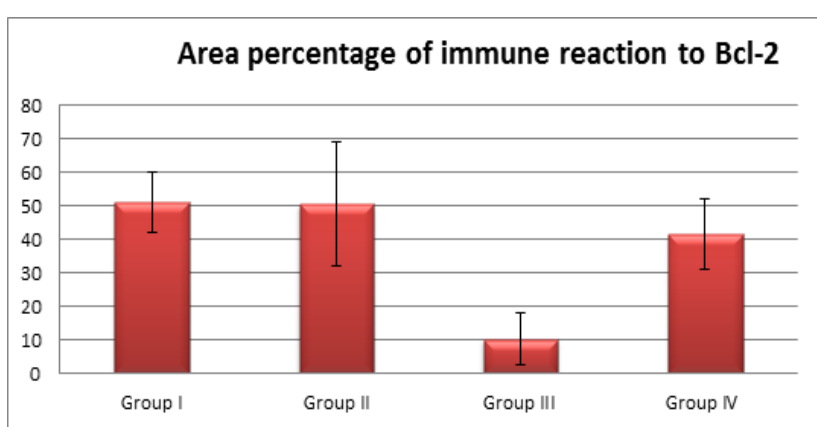

Fig. 11: The area percentage of bcl-2 immune reaction in the four studied groups

Table 1: the mean weights of rat's liver among the four studied groups (in grams)

\begin{tabular}{lll}
\hline Rat Liver Weight & Mean \pm SD & $(\mathrm{P})$ \\
\hline Group I & $7.95 \pm 0.06$ & \\
Group II & $7.88 \pm 0.08$ & $0.000^{* * *}$ \\
Group III & $10.93 \pm 0.7$ & \\
Group IV & $7.97 \pm 0.06$ & \\
\hline
\end{tabular}

**: P value is highly significant.

Table 2: The least significant difference (LSD) of liver weight (g) among the four studied groups

\begin{tabular}{lcccc}
\hline LSD & Group I & Group II & Group III & Group IV \\
\hline Group I & & $0.660 \mathrm{NS}$ & $0.000^{* *}$ & $0.897 \mathrm{NS}$ \\
Group II & $0.660 \mathrm{NS}$ & & $0.000^{* *}$ & $0.569 \mathrm{NS}$ \\
Group III & $0.000^{* *}$ & $0.000^{* *}$ & & $0.000^{* *}$ \\
Group IV & $0.897 \mathrm{NS}$ & $0.569 \mathrm{NS}$ & $0.000^{* *}$ & \\
\hline
\end{tabular}

**: highly significant NS: Non-significant

Table 3: The LSD of diameter of central vein among the four studied groups.

\begin{tabular}{lcccc}
\hline LSD & Group I & Group II & Group III & Group IV \\
\hline Group I & & $0.989 \mathrm{NS}$ & $0.000^{* *}$ & $0.000^{* *}$ \\
Group II & $0.989 \mathrm{NS}$ & & $0.000^{* *}$ & $0.000^{* *}$ \\
Group III & $0.000^{* *}$ & $0.000^{* *}$ & & $0.000^{* *}$ \\
Group IV & $0.000^{* *}$ & $0.000^{* *}$ & $0.000^{* *}$ & \\
\hline
\end{tabular}

**: highly significant NS: Non significant 
Table 4: The LSD of the area percentage of Bcl-2 immune reaction among the four studied groups.

\begin{tabular}{lcccc}
\hline LSD & Group I & Group II & Group III & Group IV \\
\hline Group I & & $0.912 \mathrm{NS}$ & $0.000^{* *}$ & $0.085^{*}$ \\
Group II & $0.912 \mathrm{NS}$ & & $0.000^{* *}$ & $0.105^{*}$ \\
Group III & $0.000^{* *}$ & $0.000^{* *}$ & & $0.000^{* *}$ \\
Group IV & $0.085^{*}$ & $0.105^{*}$ & $0.000^{* *}$ & \\
\hline **: highly significant & $*$ *: significant & NS: Non significant \\
DISCUSSION & & & \\
\hline
\end{tabular}

While the findings in the present study noted a nonsignificant difference in mean value of liver weight between group IV and the groups I and II, there was a statistical increase in liver weight in the LA treated group (III). This difference in liver weight might be due to excessive infiltration of the hepatic lobules by inflammatory cells as well as hypertrophy of hepatic arterioles and the markedly congested and dilated veins detected in group III. These findings were strengthened by previous studies ${ }^{[19,20]}$ that attributed the increase in weight of liver to hyperplasia of reticular epithelium, fibrous tissue and lipids accumulation in the liver. Moreover, Long et. $a l^{[21]}$ stated that the liver represents the major organ affected by the absorbed lead as it is the commonest repository site and the main organ implicated in biotransformation and elimination of this toxic metal.

On the contrary, other findings ${ }^{[22]}$ on experimental lead toxicity observed a significant reduction in liver weight and attributed it to mal-absorption and/or inhibition of protein synthesis.

This difference in results may be due to the much longer period of exposure in those studies, the different routes of administration or may be due to the different chemical form of lead applied in the experiment.

In the present study, ginger proved to be effective in the diminution of the toxic effects of lead on liver's vasculature and parenchyma.

Ginger's protective effect was detected by both macroscopic and microscopic examination of the liver of group IV (lead acetate and ginger treated group). Liver weight changed minimally and proved to be nonsignificant. Liver considerably preserved its normal architecture when compared with that of group III (lead acetate only). Ginger treated liver also lacks the marked inflammatory infiltration detected in that exposed only to lead acetate; this may be attributed to the potent antioxidant effect of ginger. Atta et. $a l^{[23]}$ in their investigations about the hepato-protective effect of ginger revealed similar findings were no pathognomonic changes were detected. Even more, Shrivastava ${ }^{[24]}$ in his experiment detected that treatment by ginger significantly reversed nearly all findings to the control levels.

The morphometric measurements and statistical analysis showed significant increase in the diameter of the central vein of group III as compared with that of the other three groups. On the other hand, group IV showed significant statistical increase as compared with the control groups. Gurer and Ercal ${ }^{[25]}$ pointed the possible role of reactive oxygen species (ROS) in lead-induced toxicity. ROS are highly reactive free radicals such as a superoxide ion (O2-), nitrogen oxide (NO) and hydroxyl radical $(\mathrm{OH})$ [26]. Further studies showed the role of $\mathrm{H} 2 \mathrm{O} 2$ and $\mathrm{NO}$ in causing endothelium-dependent relaxation and thus being major vasodilator factors as well as a hyperpolarizing of the vascular smooth muscle in small mesenteric arteries of mice ${ }^{[27]}$. This explains the marked changes detected in the diameters of the vessels especially the central vein.

In addition, the present study showed obvious vascular proliferation in group III, which was absent in the other groups. Previous studies showed that ROS is directly involved in nearly all the processes of angiogenesis; $\mathrm{H}_{2} \mathrm{O}_{2}$ induces both proliferation and migration of endothelial cells $^{[28]}$.

Khaki and Khaki ${ }^{[26]}$ in their study indicated that ginger is a strong anti-oxidant substance and may either mitigate or prevent generation of free radicals. This was obvious histologically in group IV which resembles greatly those of the control groups, indicating the markedly abolished ROS oxidative effect.

Such findings were in accordance also to those reported by Attia et $a{ }^{[15]}$ and Mannem ${ }^{[29]}$. The authors studied the effects of ginger supplements on lead toxicity using various doses and forms of ginger. These effects were attributed to ginger's antioxidants activity, suggesting that ginger is a protective much more than a therapeutic agent ${ }^{[10]}$.

Regarding the morphometric analysis of the area percentage of hepatocytes with positive immunoreactions for Bcl-2, group IV showed a significant statistical decrease as compared with that of both control groups. However, it showed highly significant statistical increase as compared with that of group III. This indicates an increased number of apoptotic bodies against $\mathrm{BCl} 2$ markers in group III and proves the effective rule of ginger in minimizing the apoptotic effect caused by lead toxicity on liver. These results were in agreement with previous studies ${ }^{[30,31]}$ that pointed to an anti-apoptotic property of ginger.

\section{CONCLUSION}

The ginger has an increasingly effective role in protecting hepatic cells against the toxic effects of LA. Therefore, it is recommended to advice populations at areas of unavoidable risk of lead chemicals to consume considerable amounts of ginger in anticipation to benefit from both its protective and treatment values.

\section{REFERENCES}

1. Abdou, $\mathrm{H}$ M and Hassan, $\mathrm{M} \mathrm{H}$. Protective role of omega-3 polyunsaturated fatty acid against lead acetate-induced toxicity in liver and kidney of 
female rats. BioMed research international. hindawi. [Online] 2014. [Cited: 12 31, 2017.] http://dx.doi. org/10.1155/2014/435857..

2. Lead Acetate Induced Nephrotoxicity In Wistar Albino Rats. Apathological, Immunohistochemical And Ultrasructural Studies. Sujatha, K, et al. 2, 2011, International Journal Of Pharma And Bio Sciences, Vol. 2. 0975-6299.

3. Exposure to lead in South African shooting ranges. Mathee, A, et al. 2017, Environmental Research, Vol. 153, pp. 93-98.

4. Indigofera Oblongifolia ameliorates lead acetateinduced testicular oxidative damage and apoptosis in a rat model. Dkhil, $\mathrm{M}$ A, Moneim, A E A and Al-Quraishy, S. 2, 2016, Biological trace element research, Vol. 173, pp. 354-361.

5. 5. Failure of recovery from lead induced hepatoxicity and disruption of erythrocyte antioxidant defence system in Wistar rats. . Omobowale, T O, et al. 3, 2014, Environmental toxicology and pharmacology, Vol. 37, pp. 1202-1211.

6. Effects of lead and/or cadmium on the oxidative damage of rat kidney cortex mitochondria. Wang, L, et al. 2010, Biol Trace Elem Res, Vol. 137, pp. 69-78.

7. Sub-chronic lead and cadmium co-induce apoptosis protein expression in liver and kidney of rats. Yuan, G, et al. 6, 2014, Int J Clin Exp Pathol, Vol. 7, pp. 2905-2914.

8. Toxicological assessment of combined lead and cadmium: Acute and sub-chronic toxicity study in rats. Yuan, G, et al. 2014, Food Chem Toxicol, Vol. 65, pp. 260-268.

9. Mitogen-activated protein kinase signaling and its association with oxidative stress and apoptosis in leadexposed hepatocytes. Mujaibel, L M and Kilarkaje, N. 5, 2015, Environmental toxicology, Vol. 30, pp. 513-529.

10. 10. Ginger extract modulates $\mathrm{Pb}$-induced hepatic oxidative stress and expression of antioxidant gene transcripts in rat liver. Mohamed, O L, et al. 7, 2016, Pharmaceutical biology, Vol. 54, pp. 1164-1172.

11. Pharmacotherapeutic Properties of Ginger and its use in Diseases of the Oral Cavity: A Narrative Review. Rashmi, K J and Tiwari, R. 2, 2016, Journal of Advanced Oral Research, Vol. 7.

12. Antimycobacterial and cytotoxic activity of selected medicinal plant extracts. Nguta, J M, et al. 2016, Journal of ethnopharmacology, Vol. 182, pp. 10-15.

13. Protocols for In Vitro Propagation, Conservation, Synthetic Seed Production, Microrhizome Production, and Molecular Profiling in Turmeric (Curcuma longa L.). NirmalBabu, K, et al. 2016, Protocols for In
Vitro Cultures and Secondary Metabolite Analysis of Aromatic and Medicinal Plants, Vol. Second Edition, pp. 387-401.

14. Chemical Composition and Antimicrobial Activity of Fresh Rhizome Essential Oil of Zingiber Officinale Roscoe. Sharma, P K, Singh, V and Ali, M. 2016, pain, Vol. 7, p. 8.

15. 15. Antioxidant effects of ginger (Zingiberofficinale Roscoe) against lead acetate-induced hepatotoxicity in rats. Attia, A M, et al. 20, 2014, African Journal of Pharmacy and Pharmacology, Vol. 7, pp. 1213-1219.

16. Hemodynamic and cardiac functions in rats exposed to lead toxicity, the possible effect of vitamin $\mathrm{C}$ (ascorbic acid). Saad, R A and El Sayed, M H. 7, 2014, Life Science Journal, Vol. 11, pp. 168-179.

17. Bancroft, J D and Gamble, M. Theory and practice of histological technique : . 5 th. N.Y : Churchill Livingstone, 2002.

18. Kiernan, J A. Histological and Histochemical Methods: Theory and Practice,. 4th. s.l. : Scion Publishing Ltd, 2008.

19. Indigofera oblongifolia prevents lead acetate-induced hepatotoxicity, oxidative stress, fibrosis and apoptosis in rats. Moneim, A E. 7, 2016, PLoS One, Vol. 11.

20. Effect of lead acetate toxicity on experimental male albino rat. Ibrahim, N M, et al. 1, 2012, Asian Pacific journal of tropical biomedicine, Vol. 2, pp. 41-46.

21. Proanthocyanidins Attenuation of Chronic LeadInduced Liver Oxidative Damage in Kunming Mice via the Nrf2/ARE Pathway., . Long, M, et al. 10, 2016, Nutrients, Vol. 8, p. 656.

22. Protective potential of Black grapes against lead induced oxidative stress in rats. Lakshmi, B V, Sudhakar, M and Aparna, M. 3, 2013, Environmental toxicology and pharmacology, Vol. 35, pp. 361-368.

23. Hepatoprotective Effect of Methanol Extracts of Zingiber officinale and Cichorium intybus. ATTA, A H, et al. 5, s.1. : Indian Journal of Pharmaceutical Sciences, 2010, Vol. 72, pp. 564-570.

24. The influence of gingerol treatment on aluminum toxicity in rats. Shrivastava, S. 1, s.1. : J Environ Pathol Toxicol Oncol, 2015, Vol. 34, pp. 11-21.

25. Can antioxidant be beneficial in the treatment of lead poisoning? Free Radic. Gurer, H and Ercal , N. 2000, Biol. Med., Vol. 29, pp. 927-945.

26. 26. Antioxidant effect of ginger to prevents leadinduced liver tissue apoptosis in rat. khaki, A A and Khaki, A. 14, July 18, 2010, Journal of Medicinal Plants Research, Vol. 4, pp. 1492-1495. 1996-0875.

27. Hydrogen peroxide is an endothelium-derived 
hyperpolarizing factor in mice. Matoba , T, et al. 12, Dec 15, 2000, J Clin Invest, Vol. 106, pp. 1521-1530.

28. Reactive Oxygen Species in the Vasculature: Molecular and Cellular Mechanisms. Taniyama, Y and Griendling, K K. 6, Dec 2003, Hypertension, Vol. 42, pp. 1075-81.

29. Protective effects of ginger extract against lead induced hepatotoxicity in male albino rats. Mannem, P. 5, 2014, Journal of Environmental Science, Toxicology and Food Technology, Vol. 8, pp. 53-59.

30. Journal of Medicinal Plants Research, pp. 1492-1495.

31. Genetic and Histopathological Responses to Cadmium Toxicity in Rabbit's Kidney and Liver: Protection by Ginger (Zingiber officinale). Baiomy, A A and Mansour, A A. 2, s.1. : Biol Trace Elem Res., 2016, Vol. 170, pp. 320-9. 


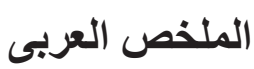

دور الزنجبيل في نموذج التسمم الكبدي بالرصاص

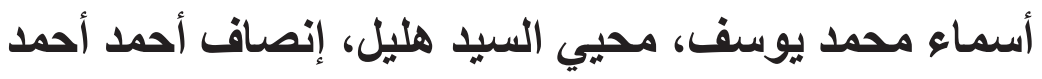

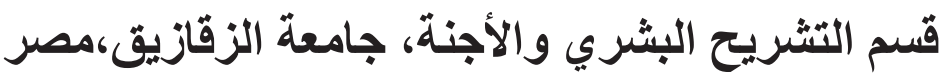

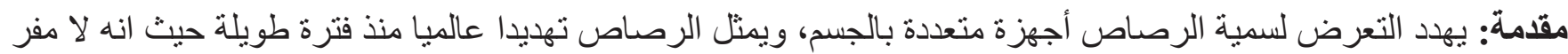

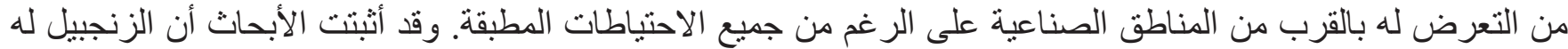

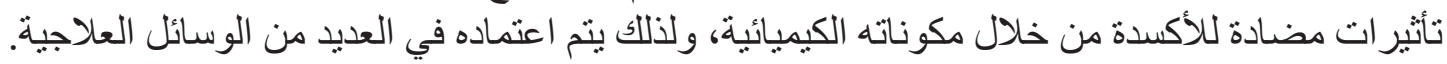

الهـف من البحث: تم تصميم هذه الدراسة لإلقاء المزيد من الضوء على على الفوائد المحتملة للزنجبيل للوقاية من تسمم الكبد

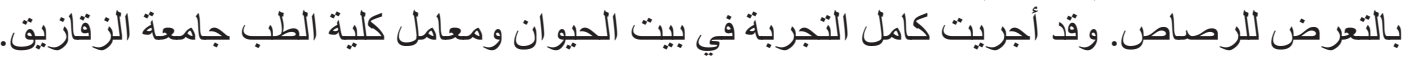

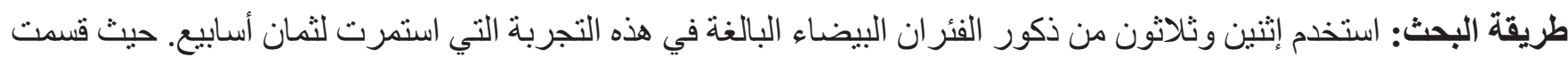

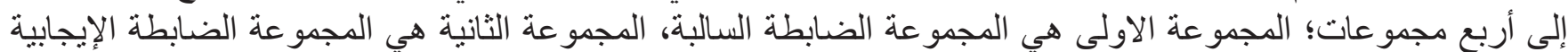

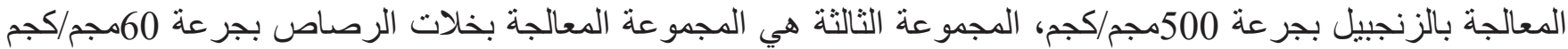

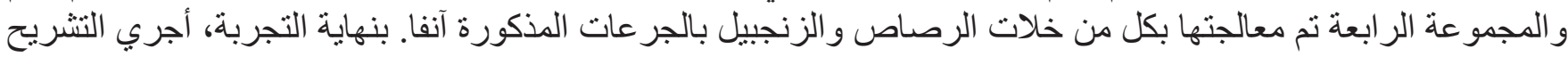

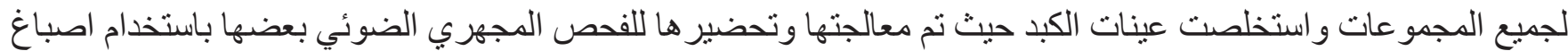
الهيماتوكسلين و الايوسين و البعض الأخر باستخدام الصبغ المناعي Bcl2 وذللك في معامل المعهد القومي للاور ام. لكي.

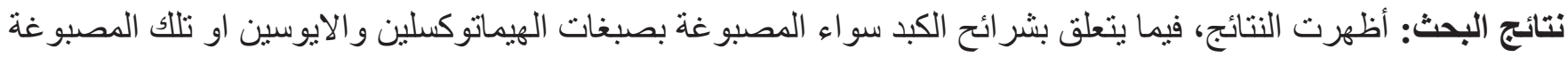

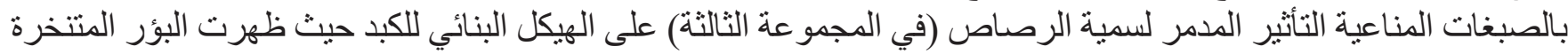

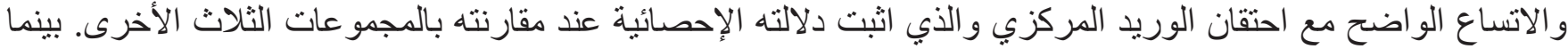

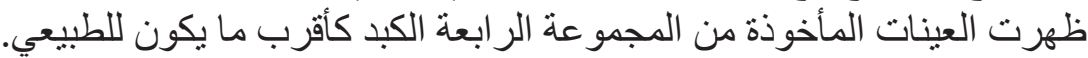

الخلاصة: يستتنج من هذه الدر اسة الثثبوت الإحصائي لتأثير ات الزنجبيل المضادة للأكسدة و أثر ها في التقليل من حدة حالات سمية الرصاص على الكبد. 